\title{
Correction to: Calling for improved quality in the registration of traditional Chinese medicine during the public health emergency: a survey of trial registries for COVID-19, H1N1, and SARS
}

Zhuoran Kuang ${ }^{1}$, Xiaoyan $\mathrm{Li}^{1}$, Jianxiong $\mathrm{Cai}^{1}$, Yaolong Chen ${ }^{2,3,4^{*}}$, Xiaoyuan Qiu ${ }^{5}$, Xiaojia $\mathrm{Ni}^{1,6^{*}}$ and on behalf of the Evidence-based Traditional and Integrative Medicine Working Group for Public Health Emergency

Correction to: Trials 22, 188 (2021)

https://doi.org/10.1186/s13063-021-05113-y

Following publication of the original article [1], we have been notified of a correction to Fig. 1 (Excluded non-TCM trials COVID-19).

The original article can be found online at https://doi.org/10.1186/s13063021-05113-y.

* Correspondence: chenyaolong@vip.163.com; grace1984325@126.com

${ }^{2}$ Evidence-based Medicine Centre, School of Basic Medical Sciences, Lanzhou University, Lanzhou 730000, China

'Guangdong Provincial Hospital of Chinese Medicine, Guangdong Provincial Academy of Chinese Medical Sciences, The Second Clinical School of Guangzhou University of Chinese Medicine, Guangzhou 510120, China

Full list of author information is available at the end of the article

(c) The Author(s). 2021 Open Access This article is licensed under a Creative Commons Attribution 4.0 International License, which permits use, sharing, adaptation, distribution and reproduction in any medium or format, as long as you give appropriate credit to the original author(s) and the source, provide a link to the Creative Commons licence, and indicate if changes were made. The images or other third party material in this article are included in the article's Creative Commons licence, unless indicated otherwise in a credit line to the material. If material is not included in the article's Creative Commons licence and your intended use is not permitted by statutory regulation or exceeds the permitted use, you will need to obtain permission directly from the copyright holder. To view a copy of this licence, visit http://creativecommons.org/licenses/by/4.0/. The Creative Commons Public Domain Dedication waiver (http://creativecommons.org/publicdomain/zero/1.0/) applies to the data made available in this article, unless otherwise stated in a credit line to the data. 
- Originally published Fig. 1:

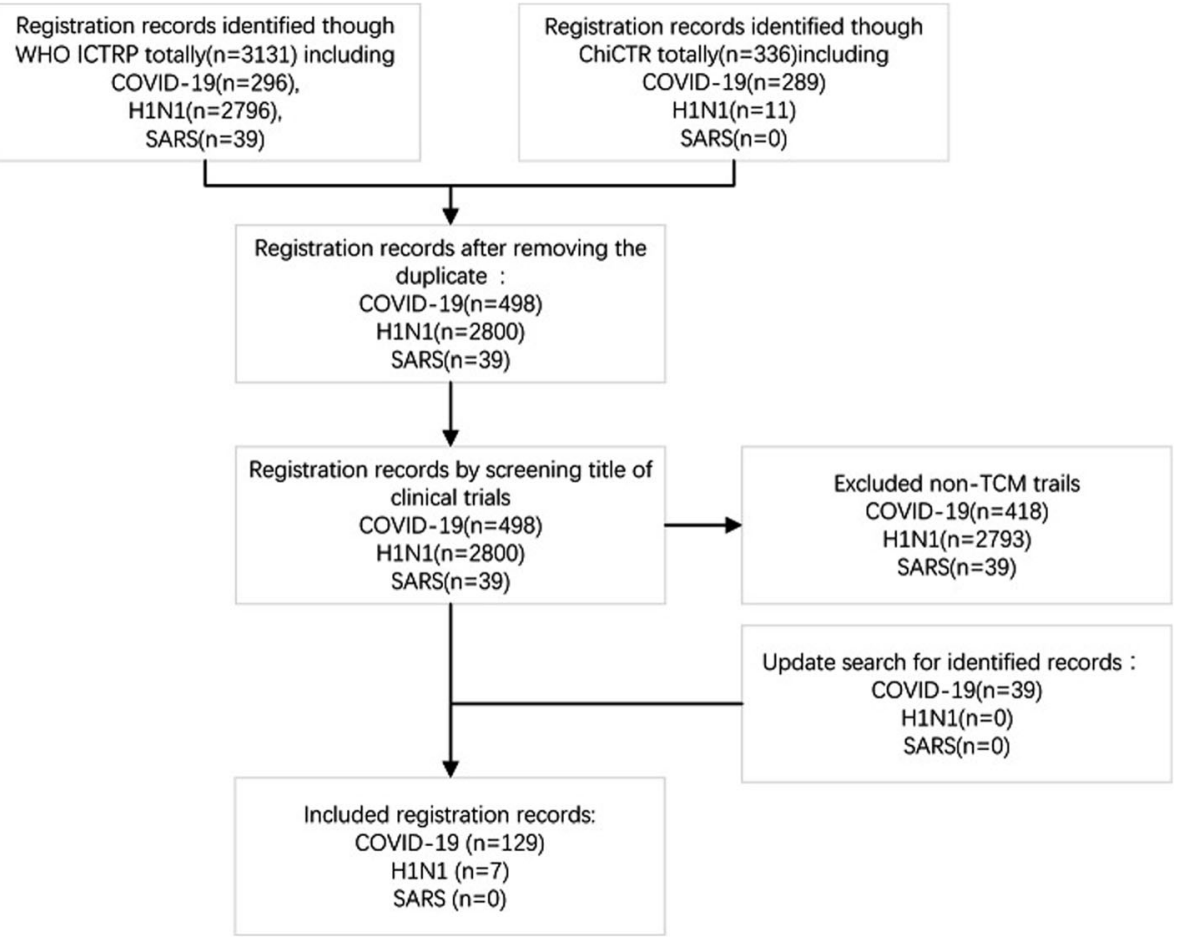

- Corrected Fig. 1:

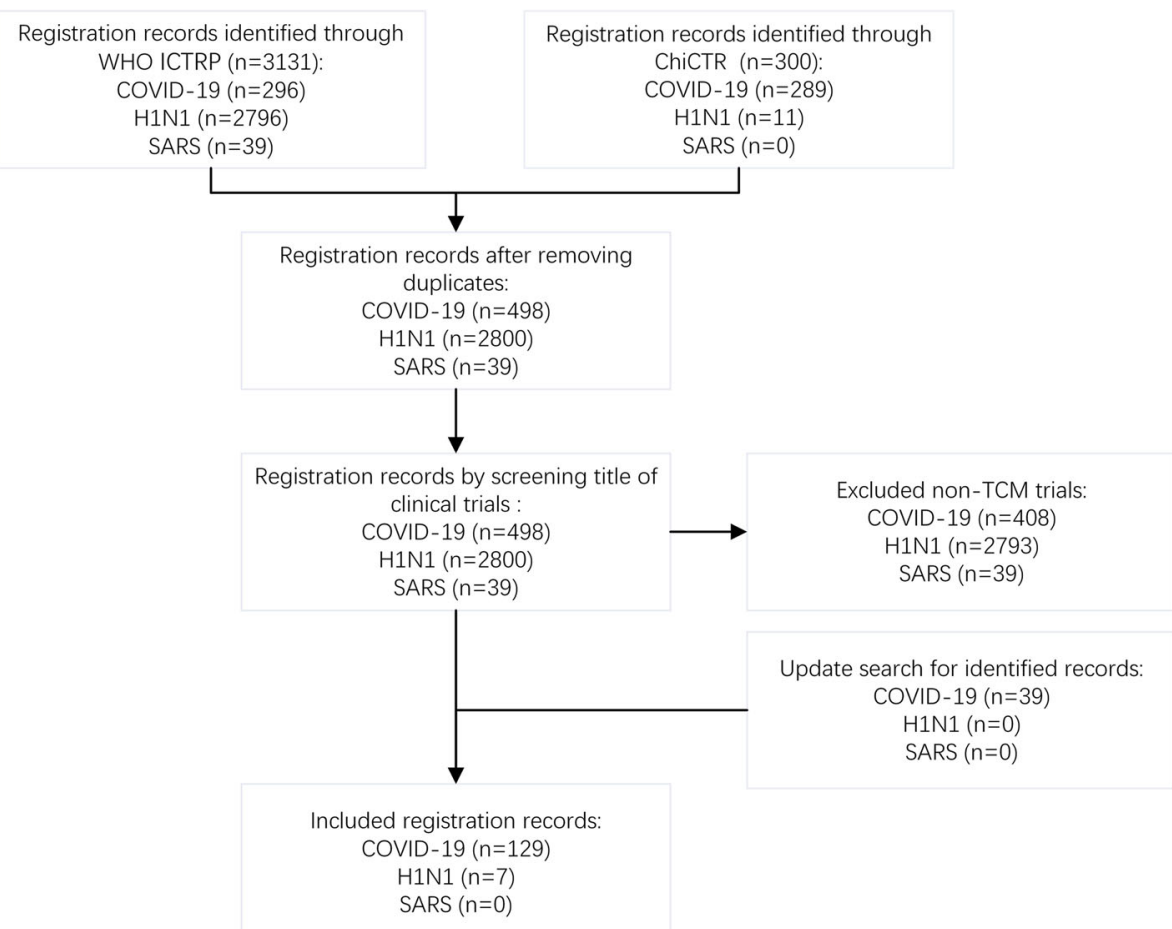

Fig. 1 Flow diagram of record screening. ICTRP, International Clinical Trials Registry Platform; ChiCTR, Chinese Clinical Trial Registry; TCM, traditional Chinese medicine; COVID-19, coronavirus disease 2019; H1N1, H1N1 influenza; SARS, severe acute respiratory syndrome 
The original article has been corrected.

\section{Author details}

${ }^{1}$ Guangdong Provincial Hospital of Chinese Medicine, Guangdong Provincial

Academy of Chinese Medical Sciences, The Second Clinical School of

Guangzhou University of Chinese Medicine, Guangzhou 510120, China.

EEvidence-based Medicine Centre, School of Basic Medical Sciences, Lanzhou

University, Lanzhou 730000, China. ${ }^{3}$ Chinese GRADE Centre, Lanzhou

University, Lanzhou 730000, China. ${ }^{4}$ WHO Collaborating Centre for Guideline Implementation and Knowledge Translation, Lanzhou 730000, China.

${ }^{5}$ Guangzhou University of Chinese Medicine, Guangzhou 510720, China.

${ }^{6}$ Guangdong Provincial Key Laboratory of Research on Emergency in TCM,

Guangzhou 510120, China.

Published online: 07 April 2021

Reference

1. Kuang Z, et al. Calling for improved quality in the registration of traditional Chinese medicine during the public health emergency: a survey of trial registries for COVID-19, H1N1, and SARS. Trials. 2021;22:188. https://doi.org/1 0.1186/s13063-021-05113-y. 